\title{
A DEFICIÊNCIA EM FOCO NOS CURRÍCULOS DE GRADUAÇÃO DA UFRN: UMA ABORDAGEM HISTÓRICA (1960-2015)
}

\author{
É. G. AMORIM*, O. M. MMEDERIOS NETA e J. GUIMARÃES \\ Universidade Federal do Rio Grande do Norte \\ erico_gurgel@hotmail.com*
}

Artigo submetido em janeiro/2016 e aceito em março/2016

DOI: $10.15628 /$ holos.2016.4000

\section{RESUMO}

A deficiência é um conceito histórico-social e, como tal, requer a sua discussão nos diversos segmentos da sociedade, os quais inclui o sistema educacional. Deste modo, o artigo objetiva mapear, no período de 1960 a 2015, os componentes curriculares dos currículos de graduação da Universidade Federal do Rio Grande do Norte (UFRN), que versam sobre a deficiência em seus diversos contextos, e também, discorrer sobre de que modo o tema da deficiência e suas concepções foram retratados nestes currículos. Utilizou-se de pesquisa exploratória e documental em base de dados eletrônica do SIGAA/UFRN, realizada no período de janeiro a março de 2015. Os resultados expressam um crescente aumento na oferta de componentes curriculares com foco na deficiência no período em estudo, notavelmente nas áreas de educação e libras. Também indicam mudanças nas denominações atribuídas ao sujeito com deficiência, bem como nas concepções e paradigmas correlatos presentes nos componentes curriculares.

PALAVRAS-CHAVE: Pessoa com deficiência, Educação especial, Inclusão educacional, Educação Superior, Currículo.

DISABILITY IN FOCUS IN UFRN GRADUATION CURRICULUM: AN HISTORICAL APPROACH (1960-2015)

\begin{abstract}
Disability is a historical-social concept and, much as, requires its discussion among the various society levels, which includes the educational system. Thus, the article aims to chart out, in the period between 1960-2015, the curricular components of the undergraduate curriculum at the Federal University of Rio Grande do Norte (UFRN), which deal with the deficiency in its various contexts, and also discuss how the theme of disability and its views were portrayed in these curriculums. We took advantage
\end{abstract}

of an exploratory and documentary research in electronic database of SIGAA / UFRN, held from January to March 2015. The results show a steady increase in the supply of curriculum components focusing on disability during the studied period, notably in areas of education and BSL (Brazilian Sign Language). They also indicate changes in the designations assigned to the people with disabilities, as well as the related concepts and present paradigms in curriculum components.

KEYWORDS: People with disabilities, Special education, Educational inclusion, College education. 


\section{INTRODUÇÃO}

Convivemos hoje com o paradigma da inclusão social, que garante ao aluno com deficiência o acesso e permanência ao sistema educacional qualificado. Apesar disso, segundo o Censo do IBGE, de 2010, as crianças com alguma deficiência estão menos presentes na escola quando comparadas às crianças sem deficiência, percentualmente. Além disso, entre deficientes com mais de 15 anos, a taxa de analfabetismo é de $18 \%$, uma diferença de 8,9 pontos percentuais em relação ao total de $9,4 \%$ (IBGE, 2010).

Quanto à formação de professores para uma educação inclusiva, apenas $77,8 \%$ dos professores que trabalham na educação especial possuem algum curso de capacitação específico nessa área de conhecimento, e apenas 75,2\% possuem nível superior (BRASIL, 2008, p. 13-14). Entretanto, a formação mínima exigida para atuação do professor nos anos finais do ensino fundamental e no ensino médio, inclusive na educação especial equivalente, é a licenciatura, em universidades e institutos superiores de educação. (BRASIL, 2013).

Tais fatos denotam uma realidade social vulnerável que expõe a pessoa com deficiência a um ciclo retroalimentador de desigualdade, segregação e desamparo, desde as fases escolares hipoassistidas à falta de qualificação profissional para o mercado competitivo, na idade adulta.

Neste cenário, a universidade, como fonte de produção de conhecimento e transformação social, cumpre importante dever de superar esta adversidade e fazer emergir novos saberes e práticas pedagógicas, por meio do ensino, pesquisa e extensão e a relação entre teoria e prática, universidade e escola.

A deficiência, nas últimas décadas, tem sido colocada como uma realidade pela qual toda a sociedade é responsável e o Estado passa a ser o promotor e garantidor desta premissa. Deste modo, a inclusão social da pessoa com deficiência assume um lema ético e moral, e um dever social, no sentido de sanar as disparidades de assistência às suas demandas cotidianas, outrora pouco atendidas.

O conhecimento de como os currículos de graduação universitários incorporam a temática da deficiência ao longo do tempo podem refletir as concepções sócio-históricas assumidas pelo entrelaçamento da sociedade com a educação e a concepção de homem vigente. Além disso, embasa a propulsão deste saber na emergência de práticas na educação especial inclusiva com a adequada atenção requerida pelo aluno com deficiência.

Nesta esteira, o presente trabalho objetiva mapear, no período de 1960 a 2015, os componentes curriculares dos currículos de graduação da Universidade Federal do Rio Grande do Norte $^{1}$ (UFRN), cujo foco é a deficiência e, também, conhecer de que modo o tema da deficiência e suas concepções foram retratados nestes currículos. O referido recorte temporal se dá por ser esse o disponível na base de dados eletrônica do Sistema Integrado de Gestão de Atividades Acadêmicas (SIGAA), da UFRN, disponível no site: https://sigaa.ufrn.br/sigaa/public/componen tes/busca_componentes.jsf?aba=p-ensino.

Assim, trata-se de uma pesquisa documental e exploratória realizada na base de dados eletrônica do Sistema Integrado de Gestão de Atividades Acadêmicas, da UFRN, disponível no site: https://sigaa.ufrn.br/sigaa/public/componentes/busca_componentes.jsf?aba=p-ensino, realizada

\footnotetext{
${ }^{1}$ A Universidade Federal do Rio Grande do Norte origina-se da Universidade do Rio Grande do Norte, criada em 25 de junho de 1958, através de lei estadual, e federalizada em 18 de dezembro de 1960.
} 
no período de janeiro a março de 2015. Por meio de mecanismo de consulta disponibilizado no site, foram pesquisados componentes curriculares no registro da instituição que apresentassem em sua denominação um dos seguintes termos: "deficiência", "deficiente", "excepcional", "portador", "disfuncional", "disfuncionalidade", "educação especial", "educação inclusiva", "educação específica", "necessidades especiais", "libras", "acessibilidade”, "acessível”, "inclusão", "inclusiva", "surdo", “mudo", "surdez", "cego", "cegueira", "braile", "retardo", "autismo", "autista", "assistiva". Esses termos foram extraídos a partir de consulta de denominações correlacionadas à pessoa com deficiência aos Descritores em Ciências da Saúde (DeCS), acrescidos de denominações obtidas a partir de textos utilizados como marco teórico no presente trabalho.

Nessa perspectiva, de conformidade com o objetivo proposto e a metodologia utilizada discorreremos sobre paradigmas, concepções e terminologia da pessoa com deficiência, bem como acerca dos marcos histórico-legais da educação especial no Brasil e, de maneira especial, sobre o mapeamento da deficiência nos currículos de graduação da UFRN, no período de 19602015.

\section{PARADIGMAS, CONCEPÇÕES E TERMINOLOGIA DA PESSOA COM DEFICIÊNCIA}

A maneira pela qual a pessoa com deficiência é referida e tratada nos diversos contextos sociais tem se modificado historicamente. Com isso, diferentes paradigmas e modelos explicativos nas relações das sociedades com a pessoa com deficiência, especificamente no que concerne à educação, são caracterizados distintamente, como já assinalaram os estudos de Figueira (2014), Diniz (2007); Gesser, Nuremberg e Toneli (2012) e Amiralian (2000).

O primeiro desses paradigmas é o de exclusão social, o qual se funda a partir do modelo metafísico ou divino de explicação da deficiência. Segundo este modelo, as deficiências eram causadas por espíritos maus, demônios ou uma forma da pessoa pagar por pecados cometidos e predominava na antiguidade. (SCLIAR, 2007; AMIRALIAN, 2000).

Já no paradigma da segregação social, a pessoa com deficiência era isolada do convívio com a sociedade, mediante internação em hospitais ou confinamento em casas de campo de sua família. Trata-se do modelo institucionalista surgido com o advento do Cristianismo, na Idade Média. ${ }^{2}$ (FUGUEIRA, 2014; PACHECO, ALVES, 2007; SILVA, 2009).

Na modernidade ${ }^{3}$, surgiu o paradigma da integração social ou de serviços. Para Brogna (2005) e Silva (2009), esse paradigma se apoia no modelo médico, devendo a pessoa com deficiência ser submetida a tratamento, curada, para ser integrada, ou reintegrada, na sociedade. Teve como marco histórico regulador o lluminismo, o qual marcou o desenvolvimento do pensamento científico-racional no século XVII. Também foi impulsionado pela Revolução Industrial e o modo de produção capitalista, que valorizavam o potencial das pessoas para o trabalho.

\footnotetext{
${ }^{2} \mathrm{~A}$ Idade Média é uma periodização que está circunscrita, tradicionalmente, ao continente europeu (século $V$ ao século $X V)$. Esse período que apresenta algumas características homogêneas e que se refere, basicamente, a Europa e, comumente, é subdividido em: Alta Idade Média (Séc. V ao IX) e Baixa Idade Média (Séc. X ao XV).

${ }^{3} A$ "época moderna", enquanto objeto de estudo, compreende o período que se estende da crise da sociedade feudal europeia no século XIV às revoluções democrático-burguesas dos séculos XVII- XVIII. Época marcada pelos processos, cujo traço comum e fundamental foi "a passagem da transcendência à imanência, da verticalidade à horizontalidade", com destaque a nova forma de situar as relações homem-natureza, a luta da Igreja contra o espírito matemáticonatural que, expressava-se através de Giordano Bruno e de Galileu Galilei. Contra a transcendência afirmar-se-ia, para a natureza e para o próprio conhecimento, o princípio da pura imanência. (MARQUES, BERUTTI, FARIA, 2005).
} 
Por último, o paradigma da inclusão social ou de suporte estabelece que a deficiência não se caracteriza pelo corpo lesado da pessoa, mas também pelas barreiras físicas, virtuais e atitudinais impostas pela sociedade. Esse paradigma tem seus pilares fundados no modelo social da deficiência, devendo a sociedade preparar-se para garantir a plena participação de todos. (DINIZ, 2007; PACHECO, ALVES, 2007; GESSER, NUREMBERG, TONELI, 2012).

Se os paradigmas para a representação e a relação da pessoa com deficiência na sociedade foram se alterando com o passar dos tempos, a denominação atribuída a quem possui uma deficiência também sofreu alterações, a exemplo: "pessoa deficiente", "portador de deficiência", "deficiente", "excepcional", "pessoa com necessidades especiais", "portadores de necessidades especiais", "pessoa com desvantagem", "pessoa com incapacidade", "pessoa com limitação", "pessoa com inaptidão física", "pessoa com discapacidade" e "pessoa com deficiência". ${ }^{4}$ (DeCS, BIREME, 2015).

No Brasil, a Constituição Federal de 1988 emprega em seu texto a expressão pessoa portadora de deficiência e a Convenção das Nações Unidas sobre os Direitos da Pessoa com Deficiência, de 2007, utiliza-se da expressão pessoa com deficiência. A Constituição Federal, de 1988, foi elaborada em um momento em que alguns termos designativos, de conotação bastante negativa, eram utilizados, tais como: surdo-mudo, aleijado, retardado e débil mental. Buscou-se então, naquele momento, uma padronização que retirasse o foco da deficiência e o colocasse na pessoa, decidindo-se por empregar a expressão designativa pessoa portadora de deficiência. Contudo, o foco ficou no "portadora" e não na pessoa, embora já se reconhecesse um avanço na nova expressão designativa. (FÀVERO, 2004).

Portanto, o termo pessoa portadora de deficiência, adotado pela Constituição Federal em vigor no Brasil e repetido pela legislação que Ihe seguiu, em evidente conduta de fidelidade ao texto maior, já denotaria uma mudança no enfoque, muito mais do que simplesmente conceitual, incluindo-se "pessoa" no núcleo da expressão. Isso permite uma primeira conclusão: a de que da ideia de defeito, de imperfeição, evoluiu-se para a de pessoa.

Para fins científicos, utilizar-se-á o termo pessoa com deficiência, empregado pela ONU na Convenção Internacional sobre os Direitos das Pessoas com Deficiência, por ser o termo que parece o mais adequado e apoiar-se no modelo social de deficiência. Não sendo apropriado o termo "portadora de deficiência", pois se refere a alguém que carrega algo consigo, como se a deficiência não fosse da pessoa, mas algo que está com a pessoa.

A convenção da ONU conceitua a pessoa com deficiência, nos termos seguintes: "Pessoas com deficiência são aquelas que têm impedimentos de longo prazo de natureza física, mental, intelectual ou sensorial, os quais, em interação com diversas barreiras, podem obstruir sua participação plena e efetiva na sociedade em igualdades de condições com as demais pessoas." (BRASIL, 2009 [ONU, 2007]).

De acordo com o modelo social, o conceito de pessoa com deficiência não deve ser obtido partindo-se unicamente da pessoa. Se a deficiência é um conceito complexo, para sua obtenção deve ser conjugado o corpo lesado com as dificuldades impostas pelo ambiente em que está situada a pessoa. Este deveria ser o raciocínio utilizado pela legislação brasileira, ao elencar o rol das deficiências e definir seus graus. No entanto, observa-se que a legislação brasileira é fundamentada no ultrapassado modelo médico sobre pessoas com deficiência, o qual leva em

\footnotetext{
${ }^{4}$ Escolhemos como parâmetro o DeCS/BIREME para a apresentação das denominações à pessoa com deficiência por considerar que a difusão do conhecimento sobre o tema é indicativo dessas alterações de terminologia.
} 
consideração, para a caracterização de uma pessoa como sendo uma pessoa com deficiência, apenas seu corpo lesado, sem analisar, portanto, sua situação no contexto social.

O Decreto n. 3.298, de 20 de dezembro de 1999, que regulamenta a Lei n. 7.853, de 24 de outubro de 1989, dispõe sobre a política nacional para a integração da pessoa com deficiência, consolida as normas de proteção e dá outras providências. Sendo esse, o diploma normativo que define e caracteriza a pessoa com deficiência. Segundo este decreto, é considerada pessoa portadora de deficiência a que se enquadra nas seguintes categorias:

a) deficiência física - alteração completa ou parcial de um ou mais segmentos do corpo humano, acarretando o comprometimento da função física, apresentandose sob a forma de paraplegia, paraparesia, monoplegia, monoparesia, tetraplegia, tetraparesia, triplegia, triparesia, hemiplegia, hemiparesia, ostomia, amputação ou ausência de membro, paralisia cerebral, nanismo, membros com deformidade congênita ou adquirida, exceto as deformidades estéticas e as que não produzam dificuldades para o desempenho de funções;

b) deficiência auditiva - perda bilateral, parcial ou total, de quarenta e um decibéis (dB) ou mais, aferida por audiograma nas frequências de $500 \mathrm{HZ}, 1.000 \mathrm{HZ}, 2.000 \mathrm{~Hz}$ e $3.000 \mathrm{~Hz}$;

c) deficiência visual - cegueira, na qual a acuidade visual é igual ou menor que 0,05 no melhor olho, com a melhor correção óptica; a baixa visão, que significa acuidade visual entre 0,3 e 0,05 no melhor olho, com a melhor correção óptica; os casos nos quais a somatória da medida do campo visual em ambos os olhos for igual ou menor que $60^{\circ}$, ou a ocorrência simultânea de quaisquer das condições anteriores;

d) deficiência mental - funcionamento intelectual significativamente inferior à média, com manifestação antes dos dezoito anos e limitações associadas a duas ou mais áreas de habilidades adaptativas, tais como: comunicação; cuidado pessoal; habilidades sociais; utilização dos recursos da comunidade; saúde e segurança; habilidades acadêmicas; lazer e trabalho; e

e) deficiência múltipla - associação de duas ou mais deficiências. (BRASIL, 1999).

Segundo o referido decreto, ficam excluídas, do conceito de deficiência física, as deformidades estéticas e as que não produzam dificuldades para o desempenho de funções, pois a promoção de medidas integrativas e inclusivas devem-se restringir a quem delas necessite.

Nesse contexto, ressalta-se que um importante divisor de águas para o estudo dos direitos da pessoa com deficiência foi o legado deixado pelas duas Grandes Guerras Mundiais, que fizeram aumentar o contingente de pessoas com deficiências de locomoção, audição e visão. Contudo, o número elevado de pessoas com deficiência no Brasil não tem as guerras como causa, mas, principalmente, os acidentes de trânsito, carência alimentar e precárias condições de higiene. (ARAÚJO, 2011).

\section{DEFICIÊNCIA EM NÚMEROS E MARCOS HISTÓRICO-LEGAIS DA EDUCAÇÃO ESPECIAL NO BRASIL}

O Censo de 2010, do Instituto Brasileiro de Geografia e Estatística (IBGE), detectou que no Brasil vivem 45.606 .048 pessoas com deficiência, o que corresponde a 23,92\% da população do país. A maior concentração de pessoas com deficiência está na Região Nordeste, com $26,3 \%$ de sua 
população, o que representa uma média acima da média nacional que é de $23,92 \%$. Desta Região, o Estado do Rio Grande do Norte está entre os de maior prevalência, com um índice de 27,86\% de sua população, o que significa 882.681 pessoas, o que equivale, praticamente, à população de sua Capital, Natal (IBGE, 2010).

Os números da educação especial indicam que há no Brasil 698.768 matrículas de alunos com necessidades educacionais especiais (NEE) em classes comuns do ensino regular da educação básica ou da Educação de Jovens e Adultos, em 2014, correspondendo a 1,4\% do total de matrículas neste ano. No Rio Grande do Norte, este número é de 13.834, o qual corresponde a $1,58 \%$ do total de matriculados. (MEC/INEP/DEED, 2015).

Em relação à educação superior, há 29.034 matrículas de alunos com NEE em cursos de graduação presenciais ou à distância no Brasil, em 2013, correspondendo a 0,29\% do total de matrículas. No Rio Grande do Norte, este número é de 508, sendo 251 em instituições públicas e 257 em instituições privadas. Entretanto, este número representa apenas 0,34\% dos matriculados, revelando a necessidade de adoção de práticas incentivadoras ao acesso das pessoas com deficiência nos níveis mais elevados de ensino. (MEC/INEP/DEED, 2014).

Pois, segundo o caput do art. 50 da Constituição Federal, todos são iguais perante a lei, sem distinção de qualquer natureza, garantindo-se aos brasileiros e aos estrangeiros residentes no país a inviolabilidade do direito à vida, à liberdade, à igualdade, à segurança e à propriedade. (BRASIL, 1988).

No entanto, a noção de igualdade seria insuficiente, se tomada apenas em seu sentido formal, já que existem pessoas com necessidades diferentes, tendo aí lugar a igualdade em sentido material (DALLARI, 1988). Com isso, emerge um campo fértil e ávido por suscitar práticas inclusivas garantidoras deste direito.

Esta igualdade não significa que todos sejam física, social, mental ou ideologicamente iguais, mas que cada pessoa tenha sua individualidade, personalidade e um modo próprio de ser. Uma pessoa com deficiência não é materialmente igual a uma pessoa sem deficiência. Da mesma forma, entre si, as pessoas com deficiência não são iguais, pois cada tipo de limitação física, sensorial ou intelectual, faz com que as necessidades de cada uma sejam diferentes. O sentido material do princípio da igualdade é, então, o de tratar igualmente os iguais, e desigualmente os desiguais, na proporção de suas desigualdades.

Na perspectiva de tratar igualmente os iguais, e desigualmente os desiguais é que o direito social à educação deveria se configurar no conjunto de leis. A Constituição Federal em vigor considera a educação como direito social de todos em seu art. 6ㅇ, a inseri como direito civil e político e dever do Estado, da família e da sociedade, nos Arts. 205 a 214 . O art. 208, I e o § 1으, dessa Constituição, preveem a obrigatoriedade do ensino fundamental e seu inciso II, a universalização progressiva do ensino médio, o que é confirmado pela colaboração entre os Entes da Federação, conforme o art. 211, mediante a vinculação de receitas de impostos, de acordo com o caput do art. 212.

A Constituição tratou também do acesso à educação das pessoas com deficiência, devendo o Estado oferecer atendimento educacional especializado àquelas pessoas, preferencialmente na rede regular de ensino, Art. 208, III. (BRASIL, 1988). Com isso, a Constituição opta pelo modelo de educação inclusiva da pessoa com deficiência, devendo esta, ser preparada para se integrar naquele grupo, e ao mesmo tempo em que o grupo deve ser preparado para recebê-la. 
Mas não só os alunos e demais profissionais daquele estabelecimento de ensino, seja ele de nível fundamental, médio ou superior, devem estar preparados para receber e interagir com o aluno com deficiência, mas também o professor. Para Araújo (2012, p. 53),

Os professores devem desenvolver habilidades próprias para permitir a inclusão desse grupo de pessoas. O trabalho inclusivo refletirá a tarefa de agregar democraticamente todos agentes neste processo. A inclusão na rede regular de ensino, com o desenvolvimento de tarefas específicas - e mesmo com tarefas de apoio, para permitir a sua melhor adaptação - mostrará o grau de cumprimento do princípio da igualdade. Igualdade, direito à educação, ensino inclusivo são expressões que devem estar juntas, exigindo do professor e da escola o desenvolvimento de habilidades próprias para propiciar, dentro da sala de aula e no convívio escolar, oportunidades para todos, pessoas com deficiência ou não.

Trabalhar com as diferenças no processo de educação é tanto uma questão de aprendizagem como de ensino, cabendo ao professor buscar meios e alternativas que possibilitem a aprendizagem do aluno. (FABRÍCIO; SOUZA; ZIMMERMANN, 2007).

No percurso pela educação inclusiva, a cooperação e o bom relacionamento entre professores e alunos favorecem uma prática docente efetiva e uma superação de eventuais limitações profissionais. (SALVADOR et al., 2006).

A existência de salas ou núcleos de atendimento especializado aos alunos com deficiência não implica em infração à cláusula constitucional de inclusão, desde que o conteúdo ou apoio ali ministrados sejam de caráter complementar e em horário distinto ao das aulas regulares. Diferente é a situação de tais salas ou núcleos serem utilizados como espaços substitutivos, onde se ensinaria as mesmas disciplinas ministradas nas salas de aulas comuns, sem possibilitar o acesso e a permanência da pessoa com deficiência no mesmo espaço que os demais alunos. Nesse caso, haveria violação da cláusula de inclusão. (FÁVERO, 2004).

A educação inclusiva não é direito apenas dos alunos com deficiência, mas de todos os que de alguma maneira apresentem perfil de vulnerabilidade social, orgânica ou psíquica. Para esta efetivação, é dever de todos os membros do corpo educacional aprender a conviver com as diferenças, garantindo o desenvolvimento pleno das pessoas com deficiência, como seres humanos e cidadãos conscientes.

No plano nacional infraconstitucional, o direito à educação é regulado, basicamente, pela Lei n. 9.394, de 20 de dezembro de 1996, conhecida como Lei de Diretrizes e Bases da Educação Brasileira ou, simplesmente, LDB, que tem por princípios a liberdade e os ideais de solidariedade humana, tendo por finalidade o pleno desenvolvimento do educando, seu preparo para o exercício da cidadania e sua qualificação para o trabalho. Segundo seu art. 3ำ o ensino será ministrado com base em diversos princípios, com destaque para a igualdade de condições para o acesso e permanência na escola (inc. I); e respeito à liberdade e apreço à tolerância (inc. IV). (BRASIL, 1996).

Como materialização desses princípios, a LDB prevê que a educação especial, como a modalidade de educação escolar, seja oferecida, preferencialmente, na rede regular de ensino, para educandos com necessidades especiais. Para instrumentalizar a educação especial, a LDB prevê a prestação de serviços de apoio especializado, na escola regular, para atender às peculiaridades desses alunos, conforme Art. 58 e $\S 10$. (BRASIL, 1996).

Consoante o Art. 59 da LDB, as instituições de ensino assegurarão aos educandos com necessidades especiais currículos, métodos, técnicas, recursos educativos e organização 
específicos, para atender às suas necessidades (inc. I); e professores com especialização adequada em nível médio ou superior, para atendimento especializado, bem como professores do ensino regular capacitados para a integração desses educandos nas classes comuns (inc. III).

De conformidade com esse contexto, como a educação vem sendo pensada pelas universidades no Brasil, especificamente na UFRN? Como essa instituição apresenta a deficiência quanto cem seus currículos? A partir dessas questões discorreremos sobre a presença da temática deficiência nos currículos de graduação da UFRN, no período de 1960-2015.

\section{A DEFICIÊNCIA EM FOCO NOS CURRÍCULOS DE GRADUAÇÃO DA UNIVERSIDADE FEDERAL DO RIO GRANDE DO NORTE (UFRN) NO PERÍODO DE 1960-2015}

Hoje, a UFRN conta com 88 cursos de graduação na modalidade presencial, com 28.812 alunos matriculados. Na modalidade a distância, em nível de graduação, em 2013, a UFRN atuou com a oferta de 11 cursos em 21 polos de apoio presencial: 14 localizados no Rio Grande do Norte (sendo 4 da UFRN e 10 em convênio com prefeituras do Estado) e 7 em outros Estados: Paraíba, Pernambuco e Alagoas. No total, somando os alunos matriculados em todos os níveis de ensino da educação superior, nas modalidades presencial e a distância, a Universidade contava, em 2013, com 41.942 alunos matriculados. (BRASIL, 2014).

Essa Universidade, federalizada no ano de 1960, possuía já em sua primeira década sete componentes curriculares que versavam sobre a temática da deficiência. E, ao longo do século XXI, este número teve significativo aumento, totalizando 90 componentes curriculares, em 2015.

Considerando a pesquisa realizada na base de dados eletrônica do Sistema Integrado de Gestão de Atividades Acadêmicas, da UFRN, foi localizado o registro de 90 componentes curriculares que apresentassem em sua denominação um dos seguintes termos: "deficiência", "deficiente", "portador", "disfuncional", "disfuncionalidade", "educação especial", "educação inclusiva", "educação específica", "necessidades especiais", "libras", "acessibilidade", "acessível", "inclusão", "inclusiva", "surdo", “mudo", "surdez", "cego", "cegueira”, "braile”, "retardo", "autismo", "autista", "assistiva". 5

Para a geração das unidades temáticas, os componentes curriculares foram agrupados conforme afinidade temática e conceitual, trazidas nos títulos ou ementa. Assim, distribuímos os componentes curriculares nas seguintes áreas de conhecimento: educação, libras, saúde, tecnologias e música.

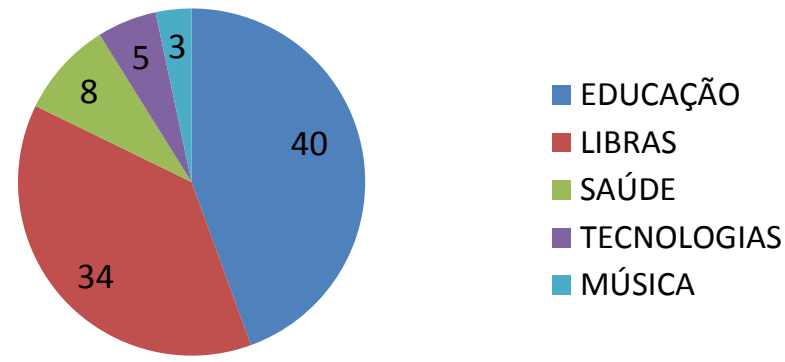

Figura 1. Distribuição dos componentes curriculares que versam sobre a deficiência na UFRN, por áreas de conhecimento

Fonte: SIGAA/UFRN.

\footnotetext{
${ }^{5}$ Esses termos foram selecionados e extraídos a partir de consulta de denominações correlacionadas à pessoa com deficiência aos Descritores em Ciências da Saúde (DeCS), conforme ressaltado anteriormente.
} 
A educação é a área de conhecimento que alberga o maior número de componentes curriculares que versam sobre a temática da deficiência, correspondendo a $44 \%$. Em seguida, seguem os componentes curriculares referentes ao ensino das libras, totalizando $38 \%$. A saúde, as tecnologias e a música albergam 9\%, 5,5\% e 3\%, respectivamente, como mostra a Figura 1.

$\mathrm{Na}$ área da educação, houve aumento expressivo na criação de novos componentes relacionados à deficiência na última década, notavelmente em 2011, com 9 componentes, seguidos por 2008 e 2009, com oito componentes cada. Conforme podemos observar na Tabela 1.

Tabela 1. Frequências acumuladas dos componentes curriculares que versam sobre deficiências na UFRN por períodos e áreas de conhecimento

\begin{tabular}{l|c|c|c|c}
\hline Áreas de conhecimento & $\mathbf{1 9 6 0 - 1 9 8 9}$ & $\mathbf{1 9 9 0 - 1 9 9 9}$ & $\mathbf{2 0 0 0 - 2 0 0 9}$ & $\mathbf{2 0 1 0 - 2 0 1 5}$ \\
\hline Educação & 4 & 6 & $\mathbf{2 6}$ & 40 \\
\hline Libras & 3 & 4 & 8 & 34 \\
\hline Saúde & 0 & 1 & 5 & 8 \\
\hline Tecnologias & 0 & 0 & 1 & 5 \\
\hline Música & 0 & 0 & 3 & 3 \\
\hline Totais & 7 & 11 & 43 & 90 \\
\hline
\end{tabular}

Fonte: SIGAA/UFRN.

Em relação a libras, houve substancial crescimento de registros de novos componentes, em 2011, com seis componentes e, em 2013, com 14 componentes. As áreas de música e tecnologias são as mais recentes a apresentarem componentes curriculares na temática da deficiência, a partir de 2005 e 2009, respectivamente. Por fim, a área da saúde apresenta oito componentes, distribuídos ao longo dos anos, a partir da década de 1990, como demonstra a Figura 2.

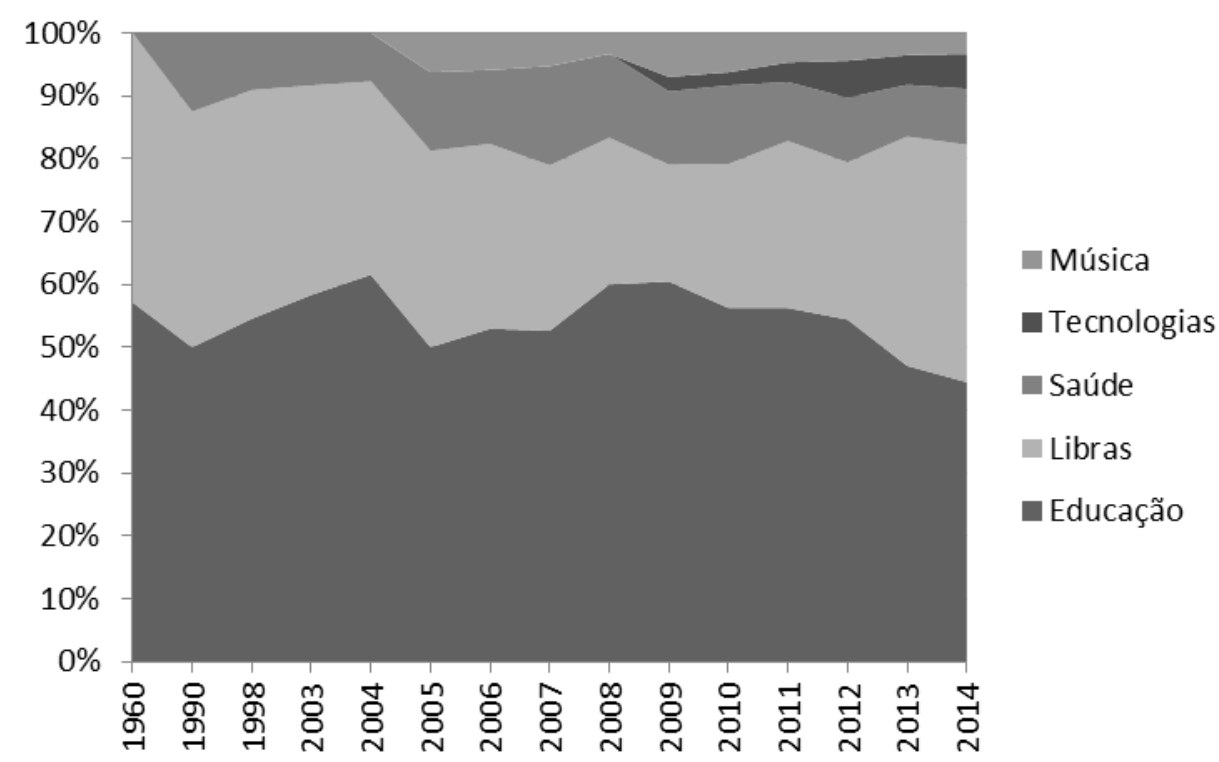

Figura 2. Frequências acumuladas dos componentes curriculares que versam sobre deficiências na UFRN por ano e áreas de conhecimento Fonte: SIGAA/UFRN.

Esses dados indiciam, em parte, os resultados de políticas educacionais impulsionadas pelo movimento a favor da inclusão do aluno com deficiência, a partir de um aparato jurídiconormativo, nas últimas décadas. Principalmente, os dados referentes à área de libras.

No cenário nacional, o campo da educação foi um dos primeiros a efetivar políticas públicas diretivas de amplo alcance para o público com alguma deficiência. A este exemplo, a Lei de 
Diretrizes e Bases da Educação Nacional n. 4.024/1961, já previa o direito dos "excepcionais" à educação, preferencialmente dentro do sistema geral de ensino. (BRASIL, 1961). Dessa forma, ficava claro que se pretendia integrar, na medida do possível, todos os alunos, com deficiências ou não, no processo educacional. Nesses termos, entendemos que os componentes curriculares voltados à deficiência na década de 1960, na UFRN, ser um indício do atendimento a essa lei e as preocupações sócio-educacionais configuradas à época.

A Constituição Federal, de 1988, reiterou a proposta de inclusão educacional do aluno com deficiência, com base nos preceitos oriundos da Declaração Universal dos Direitos Humanos, de 1948. Tal proposta se funda no princípio constitucional de igualdade de condições para o acesso e permanência na escola, compreendido como efetivação do objetivo republicano de "promover o bem de todos, sem preconceito de origem, raça, sexo, cor, idade e quaisquer outras formas de discriminação". Além disso, reforça o dever do Estado com a educação especial, efetivado mediante atendimento educacional especializado aos portadores de deficiência, preferencialmente na rede regular de ensino.

Em 1996, a Lei de Diretrizes e Bases da Educação Nacional (LDB) conceitua a educação especial como uma modalidade de educação escolar que permeia todas as etapas e níveis de ensino, desde a educação básica ao ensino superior. Trata-se de um processo educacional definido por uma proposta pedagógica que assegure recursos e serviços educacionais especiais, organizados institucionalmente para apoiar, complementar, suplementar e, em alguns casos, substituir os serviços educacionais comuns, de modo a garantir a educação escolar e promover o desenvolvimento das potencialidades dos educandos que apresentam necessidades educacionais especiais, em todas as etapas e modalidades da educação básica. (CNE, 2001).

Assim, o Conselho Nacional de Educação (CNE) instituiu as Diretrizes Nacionais para Educação Especial na Educação Básica, por meio da Resolução CNE/CEB n. 2, de 11 de Fevereiro de 2001. Neste documento, consideram-se educandos com necessidades educacionais especiais os que, durante o processo educacional, apresentarem:
a) dificuldades acentuadas de aprendizagem ou limitações no processo de desenvolvimento que dificultem o acompanhamento das atividades curriculares, vinculadas ou não a uma causa orgânica específica, como deficiências, condições, disfunções ou limitações;
b) dificuldades de comunicação e sinalização diferenciadas dos demais alunos;
c) altas habilidades ou superdotação. (CNE, 2001).

Com vistas a promover a qualidade no atendimento a essas necessidades e, consequentemente, no processo de ensino e aprendizagem, a formação docente para atuação em educação básica, inclusive na modalidade de educação especial, deverá ser realizada em nível superior, em curso de licenciatura, de graduação plena, em universidades e institutos superiores de educação. Todavia, admite-se, como formação mínima para o exercício do magistério na educação infantil e nas quatro primeiras séries do ensino fundamental, a oferecida em nível médio, na modalidade normal. (BRASIL, 1996).

Assim, a educação inclusiva pressupõe novas relações pedagógicas centradas nos modos de aprender e relações sociais que valorizam a diversidade em todas as atividades, espaços e formas de convivência e trabalho. Para isso, capacitação profissional, educação permanente, participação, acolhimento e interesse são ferramentas indelegáveis na construção de um espaço inclusivo no ambiente educacional. 
Consideradas essas questões, a educação inclusiva implica na implementação de políticas públicas, na compreensão da inclusão como processo que não se restringe à relação professoraluno, mas que seja concebido como um princípio de educação para todos e valorização das diferenças, que envolve toda a comunidade escolar. (MEC, 2006). É nesse período que a UFRN terá a implantação do maior número de componentes curriculares voltados à temática da deficiência, notadamente, no campo da educação.

Em 2011, o Decreto n. 7.611 estabelece como diretriz da política nacional de educação especial, a garantia de um sistema educacional inclusivo em todos os níveis, sem discriminação e com base na igualdade de oportunidades. (BRASIL, 2011).

Dessa forma, na efetivação do direito de todos à educação, o direito à igualdade e o direito à diferença são indissociáveis e os direitos específicos servem para eliminar as discriminações e garantir a plena inclusão social. (MEC, 2006).

Em suma, a terminologia educação especial foi precocemente utilizada na UFRN, já na década de 1960, e mantém o seu uso de maneira regular nos últimos anos. Todavia, atualmente, observa-se uma tendência à incorporação de terminologias mais específicas, com abordagens direcionadas a grupos de deficiências.

Como é o caso Língua Brasileira de Sinais (LIBRAS) que, a partir da Lei n. 10.436, de 24 de abril de 2002, foi reconhecida como um meio legal de comunicação e expressão. E, dessa forma, um instrumento propulsor da inclusão educacional do aluno com deficiência auditiva. A referida lei, ainda criou a necessidade do ensino de LIBRAS nos cursos de formação de Educação Especial, de Fonoaudiologia e de magistério dos sistemas educacionais. (BRASIL, 2002).

Segundo o Decreto n. 5.626/2005, a formação docente para o ensino de LIBRAS nas séries finais do ensino fundamental, do ensino médio e superior deverá ser realizada em nível superior em graduação plena, Letras - LIBRAS ou Letras - LIBRAS/Língua Portuguesa como segunda língua. $\mathrm{Na}$ educação infantil e nos anos iniciais do ensino fundamental, a formação deverá se dar em cursos de Pedagogia ou Curso Normal Superior, nos quais a LIBRAS e a Língua Portuguesa escrita tenham sido línguas de instrução, para que se caracterize uma educação bilíngue. Por fim, tal decreto institui o prazo de 10 anos para que as instituições de educação superior incluam LIBRAS como disciplina curricular em todos os cursos de Fonoaudiologia ou de formação de professores. (BRASIL, 2005).

O Decreto n. 7.611/2011 também previu apoio técnico e financeiro pela União aos sistemas públicos de ensino, por meio de formação continuada de professores, inclusive para o desenvolvimento da educação bilíngue para estudantes surdos ou com deficiência auditiva. (BRASIL 2011).

Em atendimento à chamada pública do governo federal, em 2012, a Universidade Federal do Rio Grande do Norte (UFRN) criou o curso de Graduação em Letras com habilitação em Língua Portuguesa e Língua Brasileira de Sinais (LIBRAS), com o objetivo de formar professores para atuarem no ensino da Língua Portuguesa como segunda língua para surdos, e da Língua Brasileira de Sinais (LIBRAS) como primeira e segunda língua no Ensino Fundamental - 60 ao 9o ano e no Ensino Médio. Isso coincide com o aumento na oferta de componentes curriculares da área de conhecimento de libras na instituição no ano de 2013 (Ver Figura 2).

Compreende-se, então, que as criações dos componentes curriculares atendem a relação da Universidade com a sociedade e suas dimensões políticas e educacionais, principalmente. Assim, no direcionamento das políticas de inclusão social da pessoa com deficiência foi cunhado o 
conceito de acessibilidade, para denotar a condição para utilização, com segurança e autonomia, total ou assistida, dos espaços, mobiliários e equipamentos urbanos, das edificações, dos serviços de transporte e dos dispositivos, sistemas e meios de comunicação e informação, por pessoa portadora de deficiência ou com mobilidade reduzida. (BRASIL, 2000; 2004) ${ }^{6}$

A acessibilidade é um princípio fundamental norteador das diretrizes gerais trazidas pelo Estatuto do Portador de Deficiência, em dezembro de 2006, com o objetivo de garantir a inclusão social plena e efetiva de pessoas em condição de desvantagem física, sensorial, mental ou intelectual.

Este conceito foi incorporado na denominação do componente curricular Tecnologia assistiva e acessibilidade, em 2014. Tal componente faz parte da grade curricular obrigatória do curso de Terapia Ocupacional e estuda os conceitos de acessibilidade, desenho universal, adaptação ambiental e dispositivos de ajuda, na perspectiva do desempenho ocupacional. Esse é apenas um dos componentes curriculares da área das Tecnologias voltadas à deficidência. Hoje, a UFRN conta com seis componentes curriculares nessa área.

Os recursos utilizáveis de tecnologia assistiva são úteis no apoio à mobilidade, atividades relacionadas à aprendizagem, trabalho, comunicação e interação social. (RODRIGUES, ALVES, 2013). O cotidiano de pessoas com deficiência é um campo fértil de sua utilização, com significativo impacto na facilitação e permissão de possibilidades de ação.

A tecnologia assistiva refere-se à área do conhecimento, de característica interdisciplinar, que engloba produtos, recursos, metodologias, estratégias, práticas e serviços que objetivam promover a funcionalidade, relacionada à atividade e participação, de pessoas com deficiência, incapacidades ou mobilidade reduzida, visando sua autonomia, independência, qualidade de vida e inclusão social. (BRASIL, 2007).

Outro campo de agregação dos componentes curriculares na UFRN é o da Música. Pois, com vistas à promoção da inclusão educacional e formação de professores para atender à crescente demanda de pessoas com deficiência visual, houve a criação de componentes curriculares no curso de licenciatura em Música. Em 2005, entrou em vigência o componente Música e Educação Especial, e em 2009, Musicografia Braile I e II, ambos com carga horária teórica e prática. Tais componentes estão em sintonia com a Lei n. 11.769/2008 que estabelece a obrigatoriedade do ensino de música nas escolas de educação básica.

Paralelamente, o crescente número de alunos com deficiência frequentando o ensino regular requer capacitação de professores para receber esta demanda, com vistas ao delineamento de uma sociedade mais inclusiva. (BEZERRA, 2014). Hipótese pela qual pode ser explicada a criação dos seis componentes curriculares voltados à articulação da música com a educação especial e, de maneira específica, com a deficiência visual. ${ }^{7}$

Na esteira da inclusão social da pessoa com deficiência e dos contributos e entraves para esta consolidação, o Departamento de Fisioterapia implementou o componente curricular Deficiência no contexto da sociedade, em 2007, com destaque ao conhecimento das

\footnotetext{
${ }^{6}$ Tal conceito está delineado pela Lei n. 10.098, de 19 de dezembro de 2000 e Decreto n. 5.296 de 2 de dezembro de 2004; bem como pelo Estatuto do Portador de Deficiência, de 2006.

${ }^{7}$ Os estudos sobre a educação musical para alunos com deficiência visual requer introdução ao sistema Braille e noções básicas do código musicográfico Braille. Este foi desenvolvido em 1827, por Louis Braille, em Paris. Trata-se de um sistema de leitura tátil eficaz e mundialmente utilizado. (BONILHA, 2006).
} 
especificidades, das necessidades e das potencialidades das pessoas com deficiência, com vistas a promover um novo conceito e mudanças de atitudes em relação a essas pessoas.

Neste sentido, a deficiência pode ser vista como uma condição complexa multideterminada, de limitação ou de impedimento da participação do indivíduo na trama de relações que compõem sua existência real concreta. (ARANHA, 1995). É, com esse entendimento, que pontuamos a criação e oferta dos componentes curriculares voltados à relação saúde e deficiência junto a UFRN. São eles: Educação Física para portadores de deficiência, Educação Física inclusiva e Deficiência no contexto da sociedade.

Estas pessoas possuem necessidades especiais devido às suas dificuldades e limitações, mas necessitam também de ter sua identidade reconhecida e romper com a tradição de uma globalização que as segrega, uma sociedade que as marginaliza e exclui.

Cabe aos órgãos e às entidades do Poder Público assegurar à pessoa portadora de deficiência o pleno exercício de seus direitos básicos, inclusive dos direitos à educação, à saúde, ao trabalho, ao desporto, ao turismo, ao lazer, à previdência social, à assistência social, ao transporte, à edificação pública, à habitação, à cultura, ao amparo à infância e à maternidade, e de outros que, decorrentes da Constituição e das leis, propiciem seu bem-estar pessoal, social e econômico. (BRASIL, 1999).

A partir do atendimento às necessidades humanas, o sujeito deficiente terá maiores possibilidades de construir ou reconstruir a dignidade de pessoa humana perante si mesmo, à família e à comunidade. Isso promoverá a aquisição ou reaquisição da autoestima, necessária à visão realista do indivíduo, abrangendo potencialidades e limites. (FIGUEIRA, 2014).

Quanto à terminologia utilizada para os componentes curriculares em escopo de análise neste trabalho, percebe-se uma evolução conceitual ao longo dos anos, o que reflete a influência dos paradigmas da deficiência dominantes em cada época, notavelmente nas áreas de conhecimento de educação, saúde e tecnologias.

As denominações utilizadas para referir-se à pessoa com algum tipo de deficiência também exprimem a construção sócio-histórica da deficiência e as políticas públicas norteadoras das ações sociais. A área da saúde cunhou em 1990, a denominação do componente curricular: Educação física para portadores de deficiência, refletindo o enfoque conceitual trazido pela Constituição Federal de 1988 e o modelo biomédico da deficiência.

Em 2009, com o reflexo das políticas educacionais e normativas federais e locais, houve incorporação da denominação de pessoas com necessidades educacionais especiais, em componentes curriculares da área de educação na UFRN. Posteriormente, em 2011, houve utilização, em componente curricular, do termo "pessoas com necessidades especiais", também na educação. Essa conceituação, embora indefinida, propõe um conjunto de ações integradas com vistas ao atendimento das necessidades do aluno com deficiência, por meio de apoio didáticopedagógico especializado.

O movimento pela inclusão da pessoa com deficiência repercutiu na terminologia dos componentes curriculares da UFRN, contundentemente, a partir de 2004. Neste ano, no campo da educação, entrou em vigência a disciplina: Educação especial inclusiva. No ano seguinte, o Departamento de Educação Física propôs o componente curricular: Educação Física inclusiva.

Mais recentemente, em 2013, a denominação do componente curricular Fundamentos da educação de surdos passou a utilizar a categoria da deficiência para se reportar ao sujeito com tal acometimento. Isso reflete um amadurecimento conceitual e um processo de normalização das situações adversas da vida, com um olhar abrangente sobre a condição humana. 


\section{CONSIDERAÇÕES}

Pelo mapeamento, no período de 1960 a 2015, dos componentes curriculares dos currículos de graduação da UFRN, cujo foco é a deficiência, e pelo conhecimento de que modo o tema da deficiência e suas concepções foram retratados na legislação e nos currículos, fica demonstrada a densidade legislativa brasileira na tentativa de amparo aos direitos constitucionais da pessoa com deficiência. Entretanto, apesar das discussões teóricas e abstratas do direito de cidadania plena de todos, é necessário romper com a retórica e praticar a liberdade, para que essas aspirações tomem concretude na dimensão positiva e resolutiva da vida humana.

A partir da crescente demanda de pessoas com deficiência no campo da educação, novos direcionamentos curriculares surgiram como importante proposta e orientação para os professores. Isso permitiu um novo marco conceitual nas relações pedagógicas com o aluno com alguma deficiência.

A UFRN tem buscado responder às exigências educacionais legais e às demandas da pessoa com deficiência a partir da formação de professores para um acolhimento e desenvolvimento pedagógico apropriados. Esses esforços remontam aos anos 1960, mas tem sido substancialmente incrementado após os anos 2000, com um crescimento consistente na quantidade de componentes curriculares que versam sobre a temática da deficiência. Entretanto, este número restringe-se, em sua maioria, às licenciaturas, não oportunizando aos alunos dos demais cursos a discussão e aprofundamento da deficiência inserida nos diversos modos de viver e agir.

Apesar dos esforços implementados pela inclusão da pessoa com deficiência, a sociedade deve romper com barreiras e preconceitos, reconhecendo o direito de tais pessoas à plena participação na vida econômica, política, social e cultural do país.

As barreiras sociais podem ser eliminadas através de campanhas de sensibilização e educação do público, para alcançar mudanças de atitudes e de comportamento com relação às pessoas com deficiência. Como diz José Antonio Ubierna (s.d.), não se muda uma sociedade por decreto, mas, sem dúvida nenhuma, o alcance da integração das pessoas portadoras de deficiência passa por superar importantes barreiras culturais e sociais. Estes obstáculos demandam tempo e estratégias distintas para a sua solução.

A Universidade, no seu papel de instituição educativa, efetiva-se pela docência e investigação. O ensino universitário, por sua vez, caracteriza-se como um processo de busca e de construção científica e crítica dos conhecimentos. (LINS, 2013).

Deste modo, a Universidade é convocada a ser o palco de discussões sobre a sociedade, mas não em termos puramente teóricos, abstratos. Deve ser o espaço em que se desenvolve um pensamento teórico-crítico de ideias, opiniões, posicionamentos, como também o encaminhamento de propostas e alternativas para solução dos problemas. (FÁVERO, 2006).

As questões curriculares estão no cerne das discussões em torno da construção de um Ensino Superior que dê conta das diversidades e diferenças. Deste modo, como instrumento de promoção a uma sólida relação com a diversidade no berço da sociedade, a partir das ideias e discussões originadas no espaço universitário, emerge a proposta de criação de componentes curriculares obrigatórios, em todos os cursos de graduação, que versem sobre a temática da deficiência nos seus diversos contextos, com vistas a romper com barreiras atitudinais, reforçando a intensa relação existente entre deficiência, cultura e sociedade. 
O discurso da liberdade e dos direitos humanos tem sido muito proclamado, mas também ainda menosprezado. Existe uma inaceitável distância entre a retórica e o fato. A cidadania verdadeira e genuína constrói-se a partir de práticas sociais intersetoriais e multifacetadas engajadas com o espírito de transformação. Só assim poderemos responder aos anseios inadiáveis de inclusão social na diversidade que habita os espaços sociais ávidos por ressignificação de saberes e sentidos.

\section{REFERÊNCIAS BIBLIOGRÁFICAS}

1. AMIRAliAN, Maria L. T. et al. Conceituando deficiência. Revista Saúde Pública, São Paulo, n. 34, v. 1, p. 97-103, 2000. Disponível em: < www.fsp.usp.br/rsp > Acesso em: 10 jan. 2015.

2. ARANHA, M. S. F. Integração social do deficiente - análise conceitual e metodológica. Temas em psicologia, Ribeirão Preto, v. 3, n. 2, ago. 1995.

3. ARAÚJO, Luiz Alberto David. A proteção constitucional das pessoas com deficiência. 4. ed. Brasília: Secretaria Nacional de Promoção dos Direitos das Pessoas com Deficiência, 2011.

4. ARAÚJO, Luiz Alberto David. A Convenção sobre os Direitos das Pessoas com Deficiência e seus reflexos na ordem jurídica interna no Brasil. (1997) In: FERRAZ, Carolina Valença et al [Coords.]. Manual dos direitos da pessoa com deficiência. São Paulo: Saraiva, 2012.

5. BEZERRA, E. V. Inclusão do aluno com deficiência visual no ensino superior: reflexões sobre a prática do professor de música. In: CONGRESSO DA ANPPOM, 24., 2014, São Paulo/SP. Anais..., 2014. p. 1-8.

6. BIREME. Descritores em Ciências da Saúde (DeCS). Disponível em: < http://decs.bvs.br > Acesso em: 2 abr. 2015.

7. BONILHA, F. F. G. Leitura musical na ponta dos dedos: caminhos e desafios do ensino de musicografia Braille na perspectiva de alunos e professores. 2006. $226 \mathrm{f}$. Dissertação (Mestrado em Música) - Instituto de Artes, Universidade Estadual de Campinas, 2006.

8. BRASIL. Lei n. 4.024, de 20 Dezembro de 1961. Lei de Diretrizes e Bases da Educação. Disponível em: < http://www.planalto.gov.br/ccivil_03/leis/l4024.htm > Acesso em: 10 mar. 2015.

9. BRASIL. Constituição da República Federativa do Brasil. Disponível em: < http://www. planalto.gov.br >. Acesso em: 10 abr. 2015.

10. BRASIL. Lei n. 7.853, de 24.10.1989. Dispõe sobre o apoio às pessoas portadoras de deficiência e dá outras providências, 1989. Disponível em: < http://www.planalto.gov.br >. Acesso em: 20 mar. 2015.

11. BRASIL. Declaração de Salamanca e linha de ação sobre necessidades educativas especiais. Brasília: UNESCO, 1994.

12. BRASIL. Lei n. 9.394, de 20 de dezembro de 1996. Estabelece as diretrizes e bases da educação nacional. Diário Oficial da União, Brasília, 23 dez. 1996.

13. BRASIL. Decreto n. 3.298, de 20 de dezembro de 1999. Regulamenta a Lei n. 7.853, de 24 de outubro de 1989, dispõe sobre a Política Nacional para a Integração da Pessoa Portadora de Deficiência, consolida as normas de proteção, e dá outras providências. Disponível em: < http://www.planalto.gov.br/ccivil_03/decreto/d3298.htm >. Acesso em: 12 mar. 2015. 
14. BRASIL. Lei n. 10088/2000. Estabelece normas gerais e critérios básicos para a promoção da acessibilidade das pessoas portadoras de deficiência ou com mobilidade reduzida, e dá outras providências, 2000. Disponível em: < http://presrepublica.jusbrasil.com.br/legisla cao/103158/lei-10088-00 >. Acesso em: 22 mar. 2015.

15. BRASIL. Conselho Nacional de Educação. Resolução CNE/CEB n. 2, de 11 de Fevereiro de 2001. Institui Diretrizes Nacionais para a Educação Especial na Educação Básica. 2001.

16. BRASIL. Lei n. 10.436 de 24 de abril de 2002. Dispõe sobre a Língua Brasileira de Sinais e dá outras providências, DF, 2002.

17. BRASIL. Ministério da Educação. Secretaria de Educação Especial. Educação inclusiva: a fundamentação filosófica. Brasília, 2004.

18. BRASIL. Decreto n. 5.626 de 22 de dezembro de 2005. Regulamenta a Lei n. 10.436, de 24 de abril de 2002 e o art. 18 da Lei n. 10.098, de 19 de dezembro de 2000, DF, 2005.

19. BRASIL. Ministério da Educação. Secretaria de Educação Especial. A política de inclusão. Brasília, 2005.

20. BRASIL. Ministério da Educação. Secretaria de Educação Especial. Direito à educação:subsídios para a gestão dos sistemas educacionais - orientações gerais e marcos legais. Brasília: MEC/SEESP, 2006.

21. BRASIL. Ministério da Educação. UFRN. Prestação de contas ordinária anual relatório de gestão do exercício de 2013. 2014. Disponível em: < http://www.sistemas.ufrn.br/portal /PT/documento/4056332\#.VTZXZyFViko > Acesso em: 3 abr. 2015.

22. BRASIL. Ata VII - Comitê de Ajudas Técnicas - CAT. Secretaria Especial dos Direitos Humanos da Presidência da República (CORDE/SEDH/PR). 2007. Disponível em: < http://www.comunicacaoalternativa.com.br/artigos-cientificos >. Acesso em: 22 mar. 2015.

23. BRASIL. Ministério da Educação. Secretaria de Educação Especial. Política Nacional de Educação Especial na Perspectiva da Educação Inclusiva. Brasília, DF. 2008.

24. BRASIL, Decreto n. 6.949, de 25 de agosto de 2009. Promulga a Convenção Internacional sobre os Direitos das Pessoas com Deficiência e seu Protocolo Facultativo, assinados em Nova York, em 30 de março de 2007 [ONU, 2007]. 2009. Disponível em: < http://www.planalto.gov.br/c civil_03/_ato2007-2010/2009/decreto/d6949.htm > Acesso: 3 abr. 2015.

25. BRASIL, Marcos Político-Legais da Educação Especial na Perspectiva da Educação Inclusiva, 2010.

26. BRASIL. Decreto n. 7.611, de 17 de novembro de 2011. Dispõe sobre a educação especial, o atendimento educacional especializado e dá outras providências. Disponível em: < http://www.planalto.gov.br/ccivil_03/_ato2011-2014/2011/decreto/d7611.htm_ > Acesso em: 10 abr. 2015.

27. BRASIL. Lei n. 12.796, de 2013. Altera a Lei n. 9.394, de 20 de dezembro de 1996, que estabelece as diretrizes e bases da educação nacional, para dispor sobre a formação dos profissionais da educação e dar outras providências. Disponível em: < http://www.planal to.gov.br/ccivil_03/_ato2011-2014/2013/lei/l12796.htm >. Acesso em: 15 fev. 2015.

28. BRASIL. Ministério da Educação e Cultura. Instituto Nacional de Estudos e Pesquisas em Educação Anísio Teixeira. Censo da Educação Superior 2013: sinopse estatística. Brasília: INEP, 2014. Disponível em < http://www.inep.gov.br/download/censo >. Acesso em: 10 mar. 2015. 
29. BRASIL. INEP. Censo Escolar, 2014. Disponível em:< http://inep.gov.br > Acesso em: 14 abr. 2015.

30. BROGNA, P. El Derecho a la Igualdad... ¿O el Derecho a la Diferencia? El Cotidiano. Universidad Autónoma Metropolitana - Azcapotzalco, Distrito Federal, México, n. 134, v. 21, nov. dez./2005, p. 43-55.

31. CAETANO, Andressa Mafezoni. A formação inicial de professores na perspectiva da inclusão escolar de alunos com deficiência: o Curso de Pedagogia da Universidade Federal do Espírito Santo. 2009. Tese (Doutorado em Educação) - Universidade Federal do Espírito Santo, 2009.

32. DALLARI, Dalmo de Abreu. Direitos humanos e cidadania. São Paulo: Moderna, 1988.

33. DINIZ, Debora. O que é deficiência? São Paulo: Editora Brasiliense, 2007.

34. FABRÍCIO, Nívea Maria de Carvalho; SOUZA, Vânia Carvalho Bueno de; ZIMMERMANN, Vera B. Singularidade na inclusão: estratégias e resultados. São José dos Campos: Pulso, 2007.

35. FÁVERO, Maria de Lourdes de Albuquerque. A Universidade no Brasil: das origens à Reforma Universitária de 1968. Educar, Curitiba, n. 28, p. 17-36, 2006.

36. FÁVERO, Eugênia Augusta Gonzaga de. Direito das pessoas com deficiência. 2004 p. 21-22. Disponível em: < http://egov.ufsc.br/portal/sites/ default/files/anexos/15675- 15676-1PB.pdf > Acesso em: 12 ago. 2013.

37. FIGUEIRA, Emílio. Introdução à psicologia e pessoas com deficiência. A construção de um novo relacionamento!. 2. ed. São Paulo: Edição do Autor/AgBook, 2014.

38. GESSER, M., NUREMBERG, A. H., Toneli, M. J. F. A contribuição do modelo social da deficiência à psicologia social. Psicologia \& Sociedade, Belo Horizonte, v. 24, n. 3, p. 557-566, 2012.

39. GUASSELLI, Maristela. Formação de professores para educação especial: fronteiras entre a produção do ensino/pesquisa e a prática na educação básica. In: ANPED SUL - Seminário de Pesquisa em Educação da Região Sul, 9., 2012, Anais..., 2012.

40. MARQUES, Ademar; BERUTTI, Flávio; FARIA, Ricardo (Orgs). História Moderna através de textos. São Paulo: Contexto. 2005.

41. PACHECO, Kátia Monteiro De Benedetto; ALVES, Vera Lucia Rodrigues. A história da deficiência, da marginalização à inclusão social: uma mudança de paradigma. Acta fisiátrica;14(4), dez. 2007.

42. SALVADOR, Diego Salomão Candido de O; MOURA, Dante Henrique; SILVA, José Aldivan de A; MAIA, Silvan Ferreira. Processo educacional inclusivo: das discussões teóricas à necessidade da prática. Holos, Natal, n. 22, p. 11-23, dez. 2006. Disponível em: < http://www2.ifrn.edu. br/ojs/index.php/HOLOS/article/viewFile/15/12 > Acessos em> 20 mar. 2015.

43. MELO, Francisco Ricardo Lins Vieira. Inclusão no ensino superior: docência e necessidades educacionais especiais. Natal: EDUFRN, 2013.

44. RODRIGUES, Patrícia Rocha; ALVES. Lynn Rosalina Gama. Tecnologia assistiva - uma revisão do tema. Holos, Natal, n. 29, v. 6, p. 170-180, 2013. Disponível em: < http://www2.ifrn.edu .br/ojs/index.php/HOLOS/article/viewFile/1595/765 > Acesso em: 27 mar. 2015.

45. SCLIAR, Moacyr. História do conceito de saúde. Physis - Revista de Saúde Coletiva, Rio de Janeiro, v. 17, n. 1, p. 29-41, jan./abr. 2007. Disponível em: < http://www.scielo.br/pdf/phy sis/v17n1/v17n1a03 > Acesso em: 2 abr. 2015. 
46. SILVA, Maria Odete Emygdio da. Da exclusão à inclusão: Concepções e práticas. Revista Lusófona de Educação, Lisboa, n. 13, p. 135-153, 2009. Disponível em: < www.scielo.oces.mctes.pt/pdf/rle/n13/13a09 > Acesso em: 20 mar. 2015.

47. UBIERNA, José Antonio. Hacia un entorno físico acessible a todos: possible o utópico, Mimeografado. (s.d.). 